\title{
Acceptability of different oral dosage forms in paediatric patients in hospital setting
}

Varsha Pokharkar ${ }^{1}$, Manjusha Sajith ${ }^{1}$, Thibault Vallet ${ }^{2}$, Fabrice Ruiz², Shruti Akshantal ${ }^{1}$, Rathin Shah ${ }^{1}$, and Smita Salunke*3

${ }^{1}$ Department of Pharmaceutics, Poona College of Pharmacy, Bharati Vidyapeeth (Deemed University), Erandwane, Pune 411038, India

${ }^{2}$ ClinSearch, 110 Avenue Pierre Brossolette, 92240 Malakoff, France

${ }^{3}$ Department of Pharmaceutics, University College London School of Pharmacy, 29-39

Brunswick Square, London WC1N 1AX, United Kingdom

\section{Correspondence to}

Smita Salunke, Department of Pharmaceutics, University College London School of Pharmacy, 29-39 Brunswick Square, London WC1N 1AX, United Kingdom. Email: s.salunke@ucl.ac.uk Tel.: +44 2077535846; Fax: +44 2077535942.

Keywords: Dosage Form, Pharmaceutical preparations, age appropriate, child, medicines, administration and dosage

Word count: 2556 (including the reference numbers in the text)

Funding statement: This research received no specific grant from any funding agency in the public, commercial or not-for-profit sectors'

\section{Contributorship statement}

F.Ruiz and T.Vallet: conceptualised and designed the study; TV: provided support in the design of the study towards the calculation of the sample size; conducted the data analysis, reviewed and revised the manuscript and approved the manuscript as finally submitted.

S.Salunke and V. Pokharkar : supervised the conceptualisation and design of the study, supervised the recruitment process and data collection, reviewed and revised the manuscript and approved the final manuscript as submitted.

M.Sajith: provided support in the design of the study towards the participant recruitment and was responsible for internal affairs at the hospitals.

M. Sajith, R. Shah and S. Akshantal coordinated the participant recruitment, collected data/responses from patients and supported manuscript preparation through data analysis.

S Salunke drafted the initial manuscript and approved the final manuscript as submitted.

V. Pokharkar, M Sajith F, Ruiz and T. Vallet reviewed and revised the manuscript and approved the final manuscript as submitted 


\section{Abstract}

Objective: The understanding of acceptability of existing dosage forms is limited in most of the world and hinders the development of acceptable, age-appropriate medicines. The attributes of paediatric medicine acceptability may differ from country to country based on culture, healthcare infrastructure, and health policies. This study was designed to map the acceptability of oral medicines in paediatric patients treated in hospital in India. Methods: An observational, cross-sectional study was conducted in patients aged below 18 years and taking any form of oral medication. Acceptability scores were obtained using CAST-ClinSearch Acceptability Score Test ${ }^{\circledR}$ tool. Findings: 490 patients were recruited and 193 evaluations of different pharmaceutical products available in 20 dosage forms and 7 routes of administration were studied. Oral liquids (55\%) and tablets (35\%) were the most commonly prescribed and administered forms. $65 \%$ expressed a positive reaction towards the acceptance of the medication. Regardless of the therapeutic class, the oral liquids were "positively accepted" in infants and toddlers. Acceptability of tablets improved with age and appeared to be generally good from the age of six. Different manipulation practices were used to ease administration of tablets in younger population such as crushing the medication, dividing dose intake, and using food or drink. Conclusion: This study fills gap in the literature and provides new insight into several central questions associated with acceptability. It examines specifically the prescription pattern of dosage forms with respect to age, the key challenges posed by the adoption and implementation of existing medicines for children in India. 


\section{Introduction}

Improving the understanding of the acceptability of different dosage forms for children is currently an area of high interest, to help address the global issue of lack of age-appropriate medicines for children and widespread off-label/unlicensed medicines use in paediatric population(1,2). There is a disagreement between regulators, paediatricians and parents on the most appropriate oral dosage form for paediatric subset. This hinders the development of age-appropriate medicines for children. This somewhat can be attributed to lack of sufficient consistent evidence required to make informed decision on acceptability and preference of dosage forms in different age groups. Most of the acceptability studies published are conducted in Europe and United States (US)(3-6). However, the attributes of acceptability that are important to this cohort may differ from country to country based on culture, healthcare infrastructure, and health policies. Hence, it is important to gauge the factors that may hinder the acceptability of dosage forms in children in different countries. World Health organisation (WHO) also have highlighted need for the methodological research on assessing the acceptability and that the economic and cultural context in which children live and ease of administration in both hospital and home care setting should be taken into consideration in development of appropriate formulations for children(7). This observational study was conducted in a hospital in India, to investigate the acceptability of dosage forms in local paediatric population.

\section{Methods}

\section{Study Design and Setting}

This prospective, cross-sectional, observational study was carried out in the outpatient department of a tertiary care hospital in Pune, India. Approval was obtained by the Institutional Ethics Committee of Bharati Hospital and Medical College, Pune (BVDUMC/IEC/11).

\section{Participants and Recruitment}


Patients and caretakers were included without any randomization in the study as per the inclusion/exclusion criteria and study methodology summarised in Figure 1. The consent was taken from participants and assent was taken from children above 8 years.

\section{Data collection}

The medicine acceptability was evaluated using a validated methodology, ClinSearch Acceptability Score Test ${ }^{\circledR}$ (CAST) entailing a questionnaire to collect standardized evaluations of medicine intake and data analysis process to score acceptability $(5,8-12)$. Each participant was interviewed by a trained researcher and accordingly the web-questionnaire was completed as per the caretaker's and patient's response (Figure 1).

Each evaluation of one medicinal product taken by one patient in a specific context, corresponded to a particular combination of an observed measure (e.g., fully taken) for each of the nine observational variables (e.g., result of intake) which describe many aspects of acceptability.

\section{Data Analysis}

The acceptability reference framework is based on multivariate analysis mining a large set of 2,611 evaluations, comprised of those from India study herein and those collected from six other countries in both domestic and hospital settings since May 2015.

First a multiple correspondence analysis (MCA) visualised similarity between evaluations and the key relationships between the 21 observed measures into a comprehensible and lowdimensional Euclidean space: the 3D acceptability map. Similar evaluations were closed on the acceptability map and the observed measures that were often selected together in the evaluations converged on the map. Afterward, hierarchical clustering on principal components and k-means consolidation gathered the similar evaluations. The clusters defined coherent positively and negatively accepted profiles materialized by a green and a red area on the map, respectively.

The evaluations collected in India were successively partitioned into subgroups of interest according to patient age groups and medicine dosage forms. In each case, the subgroup of interest was positioned on the map at the barycentre of the selected evaluations. If a 
barycentre, along with the entire $90 \%$ confidence ellipsis surrounding it, belonged to the green area of the map, the subgroup could be classified as 'accepted'. A minimum of 30 evaluations are required to obtain a reliable acceptability score. The $R$ packages FactoMineR(13) and MissMDA(14) were utilized to perform multivariate investigation and to deal with missing information, separately.

\section{Results}

\section{Patients and Medicines}

A total of 490 paediatric patients were recruited and the use of 193 distinct pharmaceutical products were identified from the data collected (Table 1). The oral liquids including syrups, suspension, drops and solution for spray (55\%) and tablets (35\%) were the most commonly prescribed and administered forms, respectively.

Table 1: Patients and medicines characteristics for the 490 evaluations collected in the study.

\begin{tabular}{|c|c|c|c|c|c|}
\hline \multirow[t]{2}{*}{ Characteristics } & \multirow{2}{*}{$\begin{array}{c}\text { All patients } \\
(\mathrm{n}=490)\end{array}$} & \multicolumn{4}{|c|}{ Patients stratified by age } \\
\hline & & $\begin{array}{c}0 \text { to } 2 \text { years } \\
(n=176)\end{array}$ & $\begin{array}{c}3 \text { to } 5 \text { years } \\
(n=89)\end{array}$ & $\begin{array}{c}6 \text { to } 11 \text { years } \\
(n=130)\end{array}$ & $\begin{array}{c}12 \text { to } 15 \text { years } \\
(n=94)\end{array}$ \\
\hline \multicolumn{6}{|l|}{ Sex of patients } \\
\hline Girl & $172(35)^{a}$ & $66(38)$ & $40(45)$ & $44(34)$ & $22(23)$ \\
\hline Boy & $316(65)$ & $110(62)$ & $49(55)$ & $85(66)$ & $72(77)$ \\
\hline missing data & 2 & & & 1 & \\
\hline \multicolumn{6}{|c|}{ Route of administration of medicines } \\
\hline Oral & 449(92) & $170(97)$ & $81(91)$ & $112(86)$ & $85(90)$ \\
\hline Topical & $18(4)$ & $2(1)$ & $1(1)$ & $11(8)$ & $4(4)$ \\
\hline Nasal & $14(3)$ & $1(1)$ & $5(6)$ & $7(5)$ & $1(1)$ \\
\hline $\begin{array}{l}\text { Other }<2 \% \\
\text { (pulmonary, } \\
\text { parenteral, rectal, and } \\
\text { auricular) }\end{array}$ & $9(1)$ & $3(2)$ & $2(2)$ & $0(0)$ & $4(4)$ \\
\hline missing data & 1 & & & & \\
\hline
\end{tabular}

Pharmaceutical dosage forms of medicines

Liquid oral dosage forms

$\begin{array}{lccccc}\text { Syrup } & 191(39) & 90(51) & 45(51) & 48(37) & 8(9) \\ \text { Oral suspension } & 53(11) & 26(15) & 9(10) & 16(12) & 1(1) \\ \text { Solution for spray } & 13(3) & 1(1) & 5(6) & 6(5) & 1(1) \\ \begin{array}{l}\text { Drops for oral solution } \\ \text { Solid oral dosage forms }\end{array} & 11(2) & 8(5) & 0(0) & 2(2) & 1(1) \\ \text { Coated tablet } & 88(18) & 18(10) & 14(16) & 23(18) & 33(35) \\ \text { Tablet } & 83(17) & 18(10) & 11(12) & 18(14) & 36(38) \\ \text { Granules } & 10(2) & 6(3) & 1(1) & 1(1) & 2(2)\end{array}$


Other dosage forms

$\begin{array}{llllll}\text { Ointment } & 15(3) & 2(1) & 1(1) & 8(6) & 4(5) \\ \begin{array}{l}\text { Other <2\% } \\ \text { (capsule, dispersible }\end{array} & 27(5) & 7(4) & 3(3) & 8(5) & 8(9) \\ \text { tablet, solution for } & & & & & \\ \text { inhalation/injection, } & & & & & \\ \text { lotion, suspension for } & & & & \end{array}$

solution)

\begin{tabular}{|c|c|c|c|c|c|}
\hline \multicolumn{6}{|c|}{ Therapeutic subgroups of medicines $^{b}$} \\
\hline Antiepileptics & $67(14)$ & $14(8)$ & $21(24)$ & 19 (15) & $13(14)$ \\
\hline Antibacterials & $58(12)$ & $15(9)$ & $12(13)$ & $23(18)$ & $7(7)$ \\
\hline Analgesics & $55(11)$ & $23(13)$ & $10(11)$ & $16(12)$ & $6(6)$ \\
\hline Vitamins & $48(10)$ & $32(18)$ & $3(3)$ & $7(5)$ & $6(6)$ \\
\hline Antivirals & $28(6)$ & $16(9)$ & $9(10)$ & $2(2)$ & $1(1)$ \\
\hline Acid related disorders & $23(5)$ & $5(3)$ & $1(1)$ & $6(5)$ & $11(12)$ \\
\hline Psycholeptics & 22(5) & $3(2)$ & $9(10)$ & $8(6)$ & $2(2)$ \\
\hline Mineral supplements & $18(4)$ & $11(6)$ & $0(0)$ & $5(4)$ & $2(2)$ \\
\hline $\begin{array}{l}\text { Antidiarrheals } \\
\text { intestinal anti- } \\
\text { inflammatory anti- } \\
\text { infective agents }\end{array}$ & $14(3)$ & $4(2)$ & $1(1)$ & $3(2)$ & $6(6)$ \\
\hline $\begin{array}{l}\text { Antianemic } \\
\text { preparations }\end{array}$ & $14(3)$ & $6(3)$ & $1(1)$ & $2(2)$ & $5(5)$ \\
\hline Nasal preparations & $12(2)$ & $6(3)$ & $0(0)$ & $5(4)$ & $1(1)$ \\
\hline $\begin{array}{l}\text { Cough and cold } \\
\text { preparations }\end{array}$ & $10(2)$ & $1(1)$ & $5(6)$ & $4(3)$ & $0(0)$ \\
\hline $\begin{array}{l}\text { Other <2\% } \\
\text { (other nervous } \\
\text { system drugs, } \\
\text { diuretics, functional } \\
\text { gastrointestinal } \\
\text { disorders, } \\
\text { antimycobacterials, } \\
\text { antihistamines, } \\
\text { antiemetics and } \\
\text { antinauseants...) }\end{array}$ & $121(23)$ & $40(23)$ & $17(20)$ & $30(22)$ & $34(38)$ \\
\hline
\end{tabular}

\section{Acceptability of commonly prescribed dosage forms as per age group}

For all the 490 evaluations, $63 \%$ of the patients expressed a positive reaction towards the acceptance of the medication. $90 \%$ took all the prescribed dose prepared and administered by the caretaker or via self-administration.

The barycentres of 268 evaluations for oral liquids and 171 for tablets, along with the confidence ellipses surrounding them, were fully located in the green area of the acceptability map corresponding to the "positively accepted" profile (Figure 2). 
Oral liquids were well accepted regardless of the patient's age (Figure 3). The larger confidence ellipse observed for children aged 12 and over was due to the very small number of evaluations $(n=11)$. Though oral liquids were found to be positively accepted as a whole, it cannot be concluded that all the different forms under this group of oral liquids are accepted, particularly for those with an insufficient number of evaluations. Herein, syrups and suspensions could be classified as accepted but only can describe a tendency for solution for spray due to insufficient number of evaluations $(n<30)$. Additionally, there is a significant part of confidence ellipsis in the red area of the map for drops for oral solution (Supplementary data - Figure 1). $65 \%$ of the 75 oral liquid products included information on the flavour or sweetener while for $35 \%$ no information was available on inclusion of flavour or sweetener. The flavour used were mixed fruit, menthol, strawberry, pineapple and raspberry.

Tablets could be classified as "positively accepted" in children aged 6 and over. For children aged 3 to 5 years, a significant part of confidence ellipses fell within the red area of the acceptability map, and the barycentre of 36 evaluations in children aged 0 to 2 years was also located in this area, indicating that tablets were not positively accepted in children aged 0 to 5 years (Figure 4). Different manipulation practices were used to ease administration of tablets in younger population. $27 \%$ divided the intake of a required dose, $11 \%$ used administration devices that was not provided with the medication, $21 \%$ used food or drink-either mixing the drug with or taking it before/after the intake_-to mask the taste or ease swallowing. There was an alteration of the intended use for $20 \%$ of the evaluations. All the negatively connoted observed measures were reported more frequently in the younger children aged 0 to 2 years and had to be administered by the caregiver (Supplementary data - Table 1 and Table 2).

\section{Discussion}

This study is the first to systematically assess the acceptability of different dosage forms in children in India. The available studies from India are focused on prescription pattern and drug use but do not refer to the acceptability of dosage forms(15). This could reflect the lack of importance of acceptability of dosage form in paediatric population and need for this study. 
The data was collected for a broad category of medicines (20 dosage forms and 7 routes of administration) in patients up to 15 years with distinctive diseases (47 therapeutic groups). The liquid dosage forms were mostly prescribed form (55\%) followed by tablets (35\%). Majority of patients in this study were $\geq 6$ years (54\%) for whom, liquid formulations or manipulating existing dosage form remains to be the only option when no age-appropriate solid dosage form was available.Tayal.et al(16) found that some regularly prescribed medicines to children (e.g. amoxicillin, albendazole) were in tablet form and had to be fragmented, despite that they were available in liquid oral dosage forms in the state essential medicines list. Few studies have emphasised the need of educating doctors about prescribing liquid dosage forms instead of prescribing tablets or capsules that need manipulation to ease administration in younger age groups $(17,18)$. This reflects the discrepancy between the availability of the marketed paediatric medicines and the medicines needed in daily practice, which drives the prescription pattern.

Considering the liquid formulation can sometimes be only available option for treatment, there is a greater need to ensure acceptability of these preparations. Our study indicated that regardless of therapeutic area, liquid dosage forms were well accepted by overall age group from 0-15 years. This is in contrast to the similar study performed in Morocco(12). Oral liquids considered as a whole, either ready to use or to be reconstituted were positively accepted in children aged 3 and over in Morocco. The syrups were well accepted and effervescent tablets, powders for oral solution, drops, were less accepted in Moroccan study. While in this study, syrups and suspensions were well accepted by all age group, drops were less accepted and insufficient evaluations limited the understanding of acceptability of solutions. The medicine was fully or partly taken without almost any alteration or promise for reward for the liquid forms that were acceptable. However, the dose had to be divided for $41 \%$ to ease administration. The preparation steps such as reconstitution, dose division are risk factors for medication errors associated with liquid dosage forms. The irrationality in manufacturing paediatric liquid dosage forms in relation to age group is an issue and is highlighted by Naik et.al(19). The study analysed commonly used paediatric antibacterial liquid formulations in India and found 
that majority of manufacturers dispensed inadequate volume of antibacterial drugs which was not sufficient for one course of therapy. This resulted into inadequate dose, wastage of drug (residual volume), resistance, and unnecessary social and financial burden to the patient. Furthermore, the use of devices that was not provided with the products (e.g., household spoons, oral syringes, droppers) was reported by $15 \%$. Published studies have highlighted that caregivers lacked proper knowledge of use of appropriate devices and administration of proper doses to children(20). Another issue is that liquid formulation often requires multiple/high amount of excipients to address the issues with stability, palatability etc. The poor organoleptic properties are well known to negatively impact acceptability of oral liquids and hence sweeteners or flavours are used. In this study, $65 \%$ of oral liquid products included flavour or sweetener. This may have helped with the acceptability of liquids in children as was the case in the study in Tanzania that reported the preference for liquid medicines in case of young children(21). However, the sweeteners in paediatric liquid medications and its impact on oral health status of their children needs to be taken into account. Many studies have reported that the parental knowledge pertaining to the harmful effects of paediatric liquid medicines on the oral health status of their children is limited. Additionally, liquid formulations often include other excipients of concern such as preservatives, solvents, with reports of possible toxicity in paediatric patients $(22,23)$. The list of the excipients is neither included on the label nor in the patient information leaflet (PIL) in India. In general, the awareness of the concerns of exposure of excipients in liquid formulations and shortcomings of liquid formulations for paediatric patients is less in resource poor settings despite of the fact that issues associated liquid formulation are more prominent and particularly relevant to these settings(24).

The other commonly prescribed dosage forms in children in this study were tablets (35\%). The tablets were prescribed for all age groups from 0 to 15 years. Though tablets are not considered suitable for children under the age of 2 years, it was seen that $20 \%$ of children in this age group received tablets even when liquid formulations were available for some drugs such as Azithromycin. This could be due to the high cost associated with the liquid formulations. For $64 \%$ of the children (0-2 years) who were prescribed tablets, parents had to 
make modifications. Splitting, crushing tablets and mixing with food were the most frequently reported methods of administration for children aged 0 to 10 years. Previous research looking at the acceptability of tablets in children in the $\operatorname{USA}(4), \operatorname{UK}(25)$ and Europe $(26,27)$, Tanzania(21) aligns closely with the findings of this study, suggesting that although the culture, healthcare infrastructure, and health policies may be quite different, acceptability of tablets in children over 3 years and administration practices for children under 3 years were similar in India. It was seen that the tablets that were not meant to be broken or crushed such as delayed release orally disintegrating tablets (e.g., lansoprazole) were crushed and administered with oral syringe(28). This indicates that manipulation of tablets by parents was not supported by instructions.

The globally designed child-appropriate formulations are still absent in the LMICs. The WHO now recommends that for paediatric treatment, liquid dosage forms should be avoided when possible in favor of solid dosage forms, ideally dispersible, fixed-dose combination tablets if available(29). These child friendly formulations are becoming increasingly available for diseases like Malaria, HIV in LMICs. However, it may take a while for these formulations to be available for other diseases areas, becoming a first choice and replacing the need of liquid dosage forms. Moreover, evaluations of alternative to liquids such as dispersible tablets, granules, are required to effectively assess the acceptability of dosage forms. Also, generic formulations could vary a lot depending on manufacturers or countries and can have impact on acceptability(30). Hence, further investigations assessing the differences in formulations (e.g., flavour, viscosity) and its impact on acceptability are required. Meanwhile to address the issue, there is a need to integrate the importance of acceptability with appropriate administration practice in health policies in India. This may consequently have an impact on transition to child-appropriate medicine formulation. The need to ensure acceptability of medicines to children has become more represented in the published literature in recent years. Though the evidence base is growing, most of the publications are predominantly from resource-rich settings $(3,31)$ and very few from resource-limited countries(32). It is a relatively new topic for many resource-limited countries, for whom the foremost priority is to improve the 
availability and affordability of medicines for children. However, there is need to educate healthcare professionals and policy decision makers that acceptability of medicines is equally important to access of medicines. The European Medicines Agency (EMA) has included a section on acceptability in their guideline on the development of medicines for paediatric use(33). Similarly, for LMICs, the integration of evaluation of acceptability and appropriate administration of solid oral dosage forms in prescription and dispensing policies may help improve the situation. There is need of coalitions to between actors to influence development of policies and facilitate communication with communities. Hence, Paediatric Medicines and Healthcare Initiative (PMHI) has been established to foster discussions needed to develop a road map for formulation and adoption of age-appropriate medicines for children in India(34).

\section{Conclusion}

From this study, it is evident that liquid and solid oral dosage formulations are the most acceptable dosage forms children in India. The absence of age appropriate, authorised and commercially available paediatric medicines is compelling prescribing tablets to younger age group. Tablets were acceptable to children over 5 years, however the administration was often followed inappropriate manipulation practice. The relevant knowledge on oral medicines acceptability extracted from this Indian study will participate to the continuous improvement of age-appropriate dosage forms and their administration to paediatric populations. Importance of acceptability is still relatively new, even in countries with a well-established research tradition; it may take time for it to gain traction in countries without this tradition 


\section{What is known about this topic}

The development of acceptable dosage forms for children in LMIC is one of the priorities of the WHO to address childhood morbidity and mortality issues.

Children and adults differ in many aspects from the other age subsets of population and require particular considerations in medication acceptability

Selecting an appropriate adapted dosage form for children permits healthcare professionals to improve acceptability. However, the understanding of acceptability is still relatively nascent in LMICs.

\section{What this study adds}

The study helped to understand the real-time scenarios of formulations acceptability in paediatric population in hospital setting in India.

Liquid formulations are most commonly prescribed and acceptable to the overall age groups, however, their shortcomings, makes it inappropriate dosage form for children Tablets are acceptable to children over 5yrs, however the administration was often not supported with proper instructions and followed inappropriate manipulation practice

\section{Acknowledgement}

We would like to acknowledge Dr Swati Mutha, Asst Professor from Vishwakarma University, Pune, India for her kind support in collection of part of the data for the study. 


\section{References}

1. Shariff ZB, Dahmash DT, Kirby DJ, Missaghi S, Rajabi-Siahboomi A, Maidment ID. Does the Formulation of Oral Solid Dosage Forms Affect Acceptance and Adherence in Older Patients? A Mixed Methods Systematic Review. Journal of the American Medical Directors Association. 2020;21(8):1015-23.e8.

2. van Riet-Nales DA, Schobben AFAM, Vromans H, Egberts TCG, Rademaker CMA. Safe and effective pharmacotherapy in infants and preschool children: importance of formulation aspects. Archives of Disease in Childhood. 2016;101(7):662-9.

3. van Riet-Nales DA, de Neef BJ, Schobben AFAM, Ferreira JA, Egberts TCG, Rademaker CMA. Acceptability of different oral formulations in infants and preschool children. Archives of Disease in Childhood. 2013;98(9):725-31.

4. Ternik R, Liu F, Bartlett JA, Khong YM, Thiam Tan DC, Dixit T, et al. Assessment of swallowability and palatability of oral dosage forms in children: Report from an M-CERSI pediatric formulation workshop. Int J Pharm. 2018;536(2):570-81. Epub 2017/08/29.

5. Ruiz F VT, Dufaÿ Wojcicki A, Belissa É, Fontan J-E, de Pontual L, et al. . Dosage form suitability in vulnerable populations: $A$ focus on paracetamol acceptability from infants to centenarians. $\quad$ https://doi.org/10.1371/journal.pone.0221261. PLoS ONE 2019;14(8):e0221261.

6. Klingmann V SN, Lerch C, Stoltenberg I, Frömke C, Bosse HM, Breitkreutz J, Meissner T. . Favourable acceptance of mini-tablets compared with syrup: a randomized controlled trial in infants and preschool children. J Pediatr. 2013;163(6):178-32.

7. WHO. Toolkit for Research and Development of Paediatric Antiretroviral Drugs and Formulations. . World Health Organization; Geneva, Switzerland: 2018 Module 5: Acceptability Available at: https://wwwwhoint/hiv/pub/5pdf. 2018.

8. Emeryk AV, T.; Wawryk-Gawda, E.; Jędrzejewski, A.; Durmont, F.; Ruiz, F. . Acceptability of a Sublingual Drug Formulation for Respiratory Tract Infections in Children Aged 3 to 5 Years. Pharmaceutics. 2021;13(2):294.

9. Ruiz F, Vallet T, Pensé-Lhéritier AM, Aoussat A. Standardized method to assess medicines' acceptability: focus on paediatric population. J Pharm Pharmacol. 2017;69(4):40616. Epub 2016/04/26.

10. Saito J, Miyamoto S, Yamada M, Yamatani A, Ruiz F, Vallet T. Adherence and Acceptability of an Oral Antibiotic Used for the Prevention of Pediatric Urinary Tract Infection in Japan. Pharmaceutics. 2021;13(3):345.

11. Vallet T, Ruiz F, Lavarde M, PensÈ-LhÈritier A, Aoussat A. Standardised evaluation of medicine acceptability in paediatric population: reliability of a model. The Journal of Pharmacy and Pharmacology. 2018;70:42 - 50.

12. Vallet T EO, Berraho A, Cherkaoui LO, Kriouile Y, Mahraoui C, Mouane N, PenseLheritier AM, Ruiz F, Bensouda Y. . Medicines Acceptability in Hospitalized Children: An Ongoing Need for Age-Appropriate Formulations. Pharmaceutics. 2020;12(8):766.

13. Lê S, Josse J, Husson F. FactoMineR: An R Package for Multivariate Analysis. 2008. 2008;25(1):18. Epub 2008-03-18.

14. Josse J, Husson F. missMDA: A Package for Handling Missing Values in Multivariate Data Analysis. 2016. 2016;70(1):31. Epub 2016-04-04.

15. Dimri S TP, Basu S, Parmar VR. Drug use pattern in children at a teaching hospital. Indian Pediatr 2009;46(2):165-7.

16. Tayal H, Roy V, Singhal S, Dubey AP. Pediatric prescribing in tertiary care teaching hospital of Delhi (India): fragmenting medicines for use. European Journal of Pediatrics. 2020;179(9):1435-43.

17. Nadeshkumar A, Sathiadas G, Sri Ranganathan S. Rational dispensing of oral dosage forms of medicines to children at a teaching hospital in Sri Lanka. BMC Health Services Research. 2020;20(1):377.

18. UL Somasiri ST, R Fernandopulle, S Sri Ranganathan. . Antiepileptic drugs for children: Availability, suitability and acceptability. Sri Lanka Journal of Child Health. 2012;41(1):38-9. 
19. Naik PP MC, Srivastava SK. . Analysis of commonly used pediatric systemic antibacterial liquid formulations for rational drug therapy. Natl J Physiol Pharm Pharmacol. 2017;7(4):348-54.

20. Sil A, Sengupta C, Das A, Sil P, Datta S, Hazra A. A study of knowledge, attitude and practice regarding administration of pediatric dosage forms and allied health literacy of caregivers for children. Journal of Family Medicine and Primary Care. 2017;6(3):636-42.

21. Adams LV, Craig SR, Mmbaga EJ, Naburi H, Lahey T, Nutt CT, et al. Children's medicines in Tanzania: a national survey of administration practices and preferences. PLoS One. 2013;8(3):e58303-e. Epub 2013/03/06.

22. Belayneh A, Tadese E, Molla F. Safety and Biopharmaceutical Challenges of Excipients in Off-Label Pediatric Formulations. Int J Gen Med. 2020;13:1051-66.

23. Fabiano V, Mameli C, Zuccotti GV. Paediatric pharmacology: remember the excipients. Pharmacol Res. 2011;63(5):362-5. Epub 2011/01/19.

24. Gerrard SE, Walsh J, Bowers N, Salunke S, Hershenson S. Innovations in Pediatric Drug Formulations and Administration Technologies for Low Resource Settings. Pharmaceutics. 2019;11(10):518.

25. Ranmal SR, Cram A, Tuleu C. Age-appropriate and acceptable paediatric dosage forms: Insights into end-user perceptions, preferences and practices from the Children's Acceptability of Oral Formulations (CALF) Study. Int J Pharm. 2016;514(1):296-307. Epub 2016/11/20.

26. Wagner-Hattler L, Kiene K, Bielicki J, Pfister M, Puchkov M, Huwyler J. High Acceptability of an Orally Dispersible Tablet Formulation by Children. Children. 2021;8(3):194. 27. Klingmann V, Spomer N, Lerch C, Stoltenberg I, Frömke C, Bosse HM, et al. Favorable acceptance of mini-tablets compared with syrup: a randomized controlled trial in infants and preschool children. J Pediatr. 2013;163(6):1728-32.e1. Epub 2013/08/27.

28. Lansoprazole Package Leaflet: Information for the patient. Available at: http://wwwhpraie/img/uploaded/swedocuments/fbcaa348-b6b8-4de2-8a9b-33ce8afb44b7pdf.

29. Orubu ESF, Tuleu C. Medicines for children: flexible solid oral formulations. Bulletin of the World Health Organization. 2017;95(3):238-40.

30. Tuleu C, Hughes DA, Clapham D, Vallet T, Ruiz F. Acceptability of generic versus innovator oral medicines: not only a matter of taste. Drug Discov Today. 2021;26(2):329-43. Epub 2020/11/21.

31. Klingmann V SN, Lerch C, Stoltenberg I, Frömke C, Bosse HM, Breitkreutz J, Meissner T. . Favourable acceptance of mini-tablets compared with syrup: a randomized controlled trial in infants and preschool children. J Pediatr. 2013;163(6):1728 - 32.

32. Angwa LM OC, Okoth P, Nyamai R, Kamau NG, Mutai K, Onono MA. . Acceptability, adherence, and clinical outcomes, of amoxicillin dispersible tablets versus oral suspension in treatment of children aged 2-59 Months with pneumonia, Kenya: A cluster randomized controlled trial. Heliyon. 2020;6(4):e03786.

33. EMA. Committee for medicinal products for human use (CHMP). Guideline on pharmaceutical development of medicines for paediatric use. EMA/CHMP/QWP/805880/2012 Rev. 2. Available at: https://wwwemaeuropaeu/en/documents/scientific-guideline/guidelinepharmaceutical-development-medicines-paediatric-use enpdf. 2013.

34. Salunke S, Schaufelberger D, Walsh J, Pradhan V, Popli H, Bansal A, et al. Indian Paediatric Formulation Initiative (IPFI) - Rising to the challenge of formulating medicines for children in low resource settings. Available at http://wwweupfiorg/past-conferences/ 11 th-eupficonference/. 2019. 